\title{
Correlation between MMPs and their inhibitors in breast cancer tumor tissue specimens and in cell lines with different metastatic potential
}

\author{
Rita CS Figueira ${ }^{\dagger 1}$, Luciana R Gomes ${ }^{\dagger 1}$, João S Neto², Fabricio C Silva², \\ Ismael DCG Silva ${ }^{3}$ and Mari C Sogayar*1
}

Address: ${ }^{1}$ Department of Biochemistry, Chemistry Institute, University of São Paulo, São Paulo, SP, Brazil, ${ }^{2}$ Hospital do Câncer Alfredo Abrão, Campo Grande, MS, Brazil and ${ }^{3}$ Department of Gynecology, Federal University of São Paulo, São Paulo, SP, Brazil

Email: Rita CS Figueira - ritabio@iq.usp.br; Luciana R Gomes - lugomes@iq.usp.br; João S Neto - joaosiufi@gmail.com;

Fabricio C Silva - fabriciocolacino@ig.com.br; Ismael DCG Silva - ismael@centrodegenomas.com.br; Mari C Sogayar* - mcsoga@iq.usp.br

* Corresponding author †Equal contributors

Published: 14 January 2009

BMC Cancer 2009, 9:20 doi:10.1186/147/-2407-9-20

This article is available from: http://www.biomedcentral.com/I47/-2407/9/20

(C) 2009 Figueira et al; licensee BioMed Central Ltd.

This is an Open Access article distributed under the terms of the Creative Commons Attribution License (http://creativecommons.org/licenses/by/2.0), which permits unrestricted use, distribution, and reproduction in any medium, provided the original work is properly cited.

\begin{abstract}
Background: The metastatic disease rather than the primary tumor itself is responsible for death in most solid tumors, including breast cancer. The role of matrix metalloproteinases (MMPs), tissue inhibitors of MMPs (TIMPs) and Reversion-inducing cysteine-rich protein with Kazal motifs (RECK) in the metastatic process has previously been established. However, in all published studies only a limited number of MMPs/MMP inhibitors was analyzed in a limited number of cell lines. Here, we propose a more comprehensive approach by analyzing the expression levels of several MMPs (MMP-2, MMP-9 and MMP-14) and MMP inhibitors (TIMP-I, TIMP-2 and RECK) in different models (five human breast cancer cell lines, 72 primary breast tumors and 30 adjacent normal tissues).
\end{abstract}

Methods: We analyzed the expression levels of MMP-2, MMP-9 and MMP-I4 and their inhibitors (TIMP-I, TIMP-2 and RECK) by quantitative RT-PCR ( $R$ RT-PCR) in five human breast cancer cell lines presenting increased invasiveness and metastatic potential, 72 primary breast tumors and 30 adjacent normal tissues. Moreover, the role of cell-extracellular matrix elements interactions in the regulation of expression and activity of MMPs and their inhibitors was analyzed by culturing these cell lines on plastic or on artificial ECM (Matrigel).

Results: The results demonstrated that MMPs mRNA expression levels displayed a positive and statistically significant correlation with the transcriptional expression levels of their inhibitors both in the cell line models and in the tumor tissue samples. Furthermore, the expression of all MMP inhibitors was modulated by cell-Matrigel contact only in highly invasive and metastatic cell lines. The enzyme/inhibitor balance at the transcriptional level significantly favors the enzyme which is more evident in tumor than in adjacent non-tumor tissue samples.

Conclusion: Our results suggest that the expression of MMPs and their inhibitors, at least at the transcriptional level, might be regulated by common factors and signaling pathways. Therefore, the multi-factorial analysis of these molecules could provide new and independent prognostic information contributing to the determination of more adequate therapy strategies for each patient. 


\section{Background}

Among diverse cancer types, breast carcinoma stands out for its increasing incidence rates and high mortality worldwide [1]. Like most solid tumors, metastatic disease rather than the primary tumor itself is responsible for death [2-4]. The metastatic process involves a complex cascade of events, including the organized breakdown of the extracellular matrix (ECM) by matrix metalloproteinases (MMPs) [5,6]. Together, the MMPs are able to process or degrade all ECM components. Each ECM element is cleaved by a specific MMP or MMP group [7]. The activity of these proteases is tightly regulated by specific inhibitors, known as tissue inhibitors of MMPs (TIMPs) $[7,8]$. Consistent with their role in tumor progression, high levels of a number of MMPs have been shown to correlate with poor prognosis in human cancers [9-11]. Surprisingly, high levels of TIMP-1 and TIMP-2 have also been shown to predict adverse prognosis and correlate with tumor aggressiveness in several different human cancers, including breast cancer [12-14]. TIMPs expression profile could be the result of its action as a multifunctional molecule [8].

The RECK metastasis suppressor gene was isolated by screening a fibroblast expression library for CDNAs that induced flat revertants in $v$-Ki-ras-transformed NIH3T3 cells [15]. RECK encodes a membrane-associated MMP regulator protein that is able to suppress tumor invasion and metastasis by negatively regulating MMPs involved in carcinogenesis, namely: MMP-2, MMP-9 and MMP-14 (MT1-MMP) $[16,17]$. Due to these functions, RECK has been described as a good prognosis marker in several tumor types, including breast carcinomas $[18,19]$.

The ECM degradation and, consequently, the invasive and metastatic potential of tumor cells is the result of the umbalance between the activities of these multiple factors that compose the proteases/inhibitors equilibrium [20]. Furthermore, each one of these molecules is involved in different stages and processes during tumor progression $[20,21]$. Although the expression and activity profile of MMPs, TIMPs and RECK have already been described in several cell line models [22-24], few reports analyze more than one MMP or MMP inhibitor in different cell lines at the same time, using the same approach [23]. Thus, there are no studies which address the complexity of MMPs/ inhibitors system in a multi-factorial context. Moreover, there are no reports comparing expression profiles of these important modulators of the metastatic process, in both a cell line model system and in breast tumor tissue samples.

Here, we analyzed the expression levels of MMPs and their inhibitors, by qRT-PCR, in a panel of five human breast cancer cell lines displaying different degrees of invasiveness and metastatic potential and in 72 primary breast cancer and 30 adjacent non-tumor tissue specimens. The results demonstrate a significant and positive correlation between the levels of MMPs and their inhibitors both in the cell line models and in tumor tissue samples, suggesting that the expression of these molecules, at least at the transcriptional level, might be regulated by common factors and signaling pathways. Therefore, deregulation of only one of these components could be followed by alterations of several other members of the proteases/inhibitors families. Therefore, we suggest that a multi-factorial analysis is crucial to properly evaluate metastasis.

\section{Methods \\ Cell Culture and RNA extraction}

Five human breast cancer cell lines displaying different degrees of invasiveness and metastatic potential were used in this study (Table 1). $10^{4} \mathrm{cell} / \mathrm{cm}^{2}$ were seeded onto uncoated or Matrigel-coated plastic dishes and incubated for 3 or 5 days. Cells were lysed in $4 \mathrm{M}$ guanidine thiocyanate; $25 \mathrm{mM}$ sodium citrate ( $\mathrm{pH} 7.0$ ); $0.1 \mathrm{M} \beta$-mercaptoethanol) and the lysate was placed on top a Cesium chloride cushion [5.7 M cesium chloride, $25 \mathrm{mM}$ sodium acetate ( $\mathrm{pH}$ 5.0)]. Samples were ultracentrifuged $\left(100,000 \mathrm{~g}\right.$, at $20^{\circ} \mathrm{C}$ for $\left.18 \mathrm{~h}\right)$; the RNA pellet was solubilized in Milli-Q $\mathrm{H}_{2} \mathrm{O}$ and stored at $-70^{\circ} \mathrm{C}$. The RNA quality was evaluated by electrophoresis in agarose gel containing $20 \mathrm{mM}$ guanidine thiocyanate.

Table I: General characteristics of previously described human breast cancer cell lines

\begin{tabular}{|c|c|c|c|c|c|c|}
\hline Cell Line & Histopathologycal type & Origin & ER & PR & Invasive potential & Metastatic potencial \\
\hline MCF-7 & Invasive ductal carcinoma & Metastasis (pleural effusion) & + & + & + & -- \\
\hline ZR-75-I & Invasive ductal carcinoma & Metastasis (ascite) & + & + & ++ & -- \\
\hline MDA-MB-435 & Invasive ductal carcinoma & Metastasis (pleural effusion) & - & - & +++ & ++++ \\
\hline MDA-MB-23I & Invasive ductal carcinoma & Metastasis (pleural effusion) & - & - & ++++ & + \\
\hline $\mathrm{Hs} 578 \mathrm{~T}$ & Carcinosarcoma & Tumor primary & - & - & ++++ & ++++ \\
\hline
\end{tabular}

Table based on previously published data [39-4I].

ER: status of estrogen receptor; PR: status of progesterone receptor (Negative (-), Positive (+)).

alnvasive potential analyzed by chemoinvasion assays through of reconstituted basal lamina (Matrigel) in transwell plates.

bMetastatic potential verified through of spontaneous metastasis assays in immune deficient mice 


\section{Patients}

The tumor and adjacent non-tumor breast tissue samples used in this study were provided by the Tumor Bank of the A.C. Camargo Cancer Hospital and Alfredo Abrão Cancer Hospital. The study protocol was approved by the Ethics Committee of these hospitals, certifying these studies were conducted in accordance with the guidelines of the 1975 Declaration of Helsinki (Process number 20 of June $\left.24^{\text {th }}, 2006\right)$. Informed consent was obtained from all patients before or after surgery. All of these tissue fragments were obtained during mastectomy by cold scalpel. The adjacent non-tumor tissue was removed at least $4 \mathrm{~cm}$ from the tumor border. All tissue samples were dissected by a pathologist, with the help of magnifying glasses, during surgery. The samples were harvested by the pathologist and immediately transferred to liquid nitrogen. These frozen samples were processed for RNA extraction, after informed consent was obtained from the patients. The methodology used for RNA extraction from tissue specimens was that previously described for RNA extraction from cell culture. The RNA quality was evaluated by electrophoresis in agarose gel containing $20 \mathrm{mM}$ guanidine thiocyanate. The RNA samples were quantified and similar quantities were used for cDNA synthesis. Of these, 11 (15.3\%) were coded as stage I, $16(22.2 \%)$ as stage IIA, 20 $(27.8 \%)$ as stage IIB, $9(12.5 \%)$ as stage IIIA, $11(15.3 \%)$ as stage IIIB and $5(6.9 \%)$ as stage IV. Lymph nodes were evaluated in these tumors samples: 41 (56.9\%) displayed compromised lymph nodes. The status of the molecular markers estrogen receptor (ER) and progesterone receptor (PR) was analyzed in 56 tumors, of which 41 tumors (73.2\%) were positive for ER and 30 (53.6\%) for PR. These and other clinical pathological data are shown in the Additional Data (see Additional file 1).

\section{Quantitative RT-PCR}

For cDNA synthesis, $1 \mu \mathrm{g}$ of total RNA was reverse-transcribed using oligo-dT, random primers and Superscript Amplification System (Invitrogen). Quantitative RT-PCR was carried out using SYBR Green PCR Master Mix (Applied Biosystems). Table 2 shows the primers used, with the optimal concentration (in range of $100 \mathrm{nM}$ to $600 \mathrm{nM}$ ). Cycling conditions were $50^{\circ} \mathrm{C}$ for $2 \mathrm{~min}, 95^{\circ} \mathrm{C}$ for $10 \mathrm{~min}$ followed by 10 cycles of $95^{\circ} \mathrm{C}$ for $15 \mathrm{sec}$ and $60^{\circ} \mathrm{C}$ for $30 \mathrm{sec}$. For quantification, the target genes were normalized to the internal standard GAPDH, HPRT, $\beta$ actin and $\beta$-tubulin genes. The amplification efficiency analyzed was calculated for each gene from the given slope in linear regression curve of $\mathrm{Ct}$ values versus log of cDNA concentration. The corresponding PCR efficiency (E) of one cycle in the exponential phase was calculated

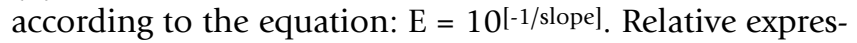
sion levels were calculated according to the previously described Pfaffl model [25].
Table 2: Sequence of primers used

\begin{tabular}{ll}
\hline Gene & Primer sequence \\
\hline MMP-2 & F: AGCTCCCGGAAAAGATTGATG \\
& R: CAGGGTGCTGGCTGAGTAGAT \\
MMP-9 & F: CCTGGAGACCTGAGAACCAATC \\
& R: GATTTCGACTCTCCACGCATCT \\
MMP-I4 & F: GCAGAAGTTTACGGCTTGCA \\
& R: TCGAACATTGGCCTTGATCTC \\
TIMP-I & F: CCGCAGCGAGGAGTTTCTC \\
& R: GAGCTAAGCTCAGGCTGTTCCA \\
TIMP-2 & F: CGACATTTATGGCAACCCTATCA \\
& R: GCCGTGTAGATAAACTCTATATCC \\
RECK & F: TGCAAGCAGGCATCTTCAAA \\
& R: ACCGAGCCCATTTCATTTCTG \\
GAPDH & F: ACCCACTCCTCCACCTTTGA \\
& R: CTGTTGCTGTAGCCAAATTCGT \\
b-tulin & F: TCAACACCTTCTTCAGTGAAACG \\
& R: AGTGCCAGTGCGAACTTCATC \\
b-actin & F: GGCACCCAGCACAATGAAG \\
& R: CCGATCCACACGGAGTACTTG \\
HPRT & F: GAACGTCTTGCTCGAGATGTGA \\
& R: TCCAGCAGGTCAGCAAAGAAT \\
\hline
\end{tabular}

\section{Zymography}

Gelatin zymography was used to analyze MMP-2 and MMP-9 protease activities in human breast cancer cell lines (Table 1). $5 \times 10^{4} \mathrm{cell} / \mathrm{cm}^{2}$ was seeded onto plastic or Matrigel-coated plastic dishes. After $48 \mathrm{~h}$, cultures were washed and replenished with their respective serum-free ATCC-recommended culture medium plus $0.1 \%$ BSA (Sigma) for $72 \mathrm{~h}$. The protein content of the serum-free conditioned medium (CM) was measured using the Bradford method. $25 \mu \mathrm{g}$ of protein of each CM were mixed with SDS sample buffer without reducing agent and heated at $50^{\circ} \mathrm{C}$ for $10 \mathrm{sec}$. Samples were resolved in $12 \%$ polyacrylamide gels copolymerized with $0.1 \%$ gelatin (Bio-Rad). After electrophoresis, gels were washed in $2 \%$ $(\mathrm{v} / \mathrm{v})$ Triton $\mathrm{X}-100$ for $15 \mathrm{~min}$ at $37^{\circ} \mathrm{C}$ to remove SDS, and then incubated in developing buffer $[50 \mathrm{mM}$ Tris- $\mathrm{HCl}$ (pH 7.4), $10 \mathrm{mM} \mathrm{CaCl}_{2}$ and $5 \mu \mathrm{M} \mathrm{ZnCl}_{2}$ ] for $16-20 \mathrm{~h}$ at $37^{\circ} \mathrm{C}$. Subsequently, gels were fixed and stained with $30 \%$ methanol and $10 \%$ glacial acetic acid containing $0.5 \%$ Coomassie blue R250 (Sigma). The protease activity was visualized as clear bands within the stained gel.

\section{Statistical Analysis}

All statistical analyses were performed with the GraphPad Prism 4.0 program. Results are presented as mean \pm standard deviation. Statistical significance was determined using Student's $t$ test for analysis of only two populations. One way ANOVA variance analysis and Tukey-Kramer test were used to calculate p-values for multiple comparisons. Pearson correlation test was used for correlation analysis. The Chi-square test was used in analysis of quantitative 
variable association. Differences were considered significant at $\mathrm{p}<0.05$.

\section{Results} mRNA expression and activity of MMPs and their inhibitors in human breast cancer cell lines

In order to determine whether MMPs and their inhibitors are responsible for the different invasive and metastatic capacities displayed by a panel of five human breast cancer cell lines (Table 1), we analyzed the expression levels of MMPs, TIMPs and RECK by qRT-PCR. The results (Fig. 1) demonstrated that the relative levels of MMP-2, MMP9, MMP-14, TIMP-1, TIMP-2 and RECK were generally higher in highly invasive and metastatic cell lines (MDAMB-435, MDA-MB-231 and Hs578T), when compared to less aggressive ones (MCF-7 and ZR-75-1). The levels of MMP-2 and MMP-14 were significantly elevated ( $\mathrm{p}<$ 0.001 ) in the Hs578T cell line relative to those of less aggressive cell lines. The MDA-MB-231 cell line displayed significantly higher mRNA levels of MMP-9 and MMP-14
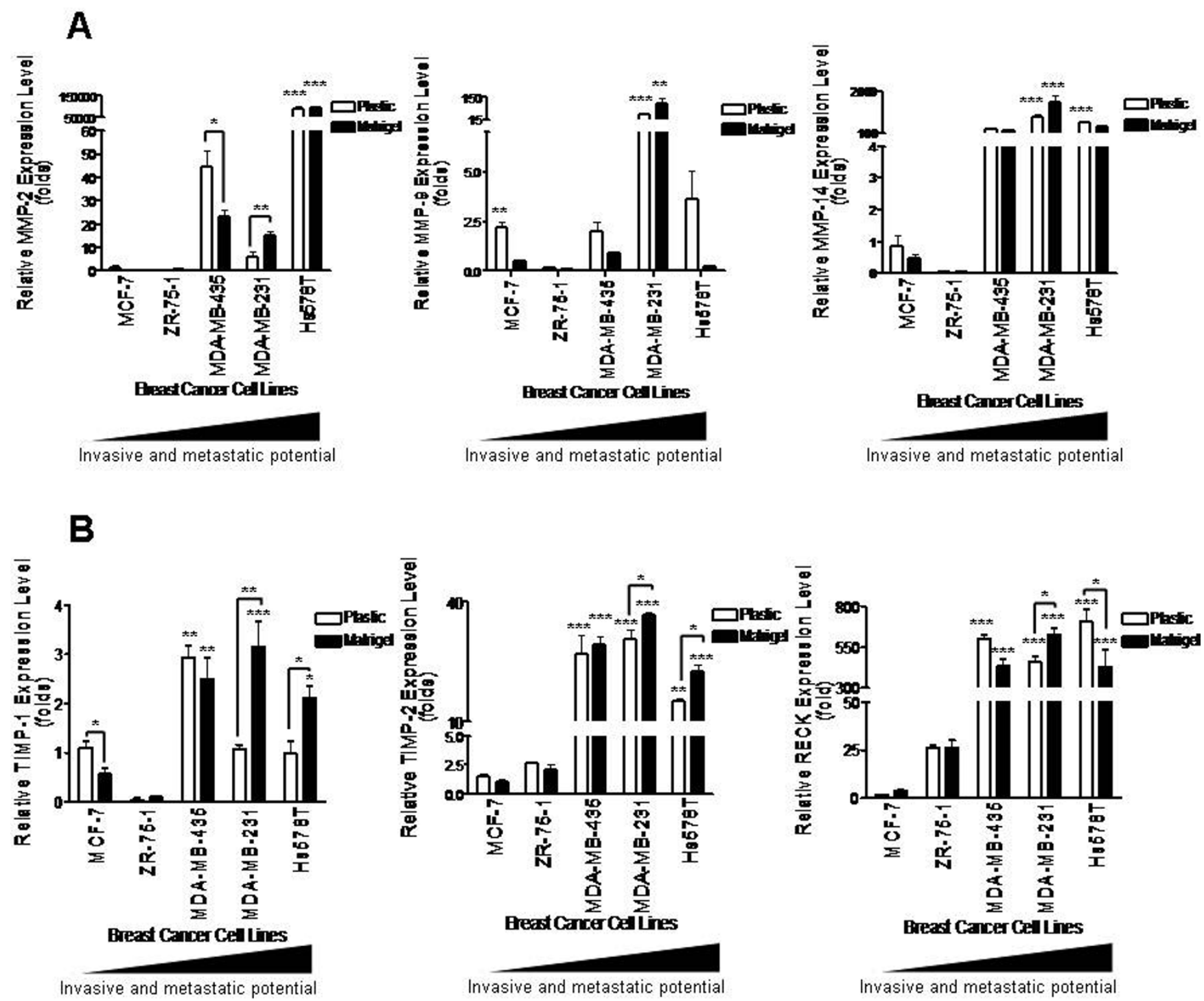

Figure I

Expression levels of MMPs (A) and their inhibitors (B) by qRT-PCR using total RNA from a panel of five human breast cancer cell lines, displaying increased degrees of invasiveness and metastatic potential, cultured on different substrates (plastic or Matrigel). GAPDH was used to normalize the values. Results are presented as MEANS \pm SD of two independent experiments. $P$ values were derived from One-way analysis of variance and Tukey-Kramer test. *, $P<0.05$; $* *, \mathrm{p}<0.01$ and $* * * \mathrm{p}<0.001$, all versus control (MCF-7). 
than MCF-7 ( $\mathrm{p}<0.001)$. In most cases, the MDA-MB-435 cell line showed a similar tendency, but it was not statistically significant. Moreover, all analyzed MMPs inhibitor (TIMP-1, TIMP-2 and RECK) are also over-expressed in MDA-MB-435, MDA-MB-231 and Hs578T breast cancer cells. The TIMP-1 gene expression was significantly higher in MDA-MB-435 than MCF-7 ( $\mathrm{p}<0.01)$. The others analyzed MMP inhibitors (TIMP-2 and RECK) displayed statically significant increased mRNA expression levels in all highly invasive and metastatic cell lines used in this study when compared with MCF-7 ( $\mathrm{p}<0.001$, except to TIMP-2 expression in Hs578T whose statistical significance was $\mathrm{p}$ $<0.01$.

Given that cell-ECM interaction regulates gene expression, we investigated the possible role of this interaction in the control of expression and activity of MMPs and their inhibitors. We cultured these human breast cancer cell lines on plastic or on artificial ECM (Matrigel) and then assessed MMPs and their inhibitors expression and activity. Among MMPs, only MMP-2 expression was significantly regulated by cell-ECM interaction, and only in MDA-MB-435 ( $\mathrm{p}<0.05)$ and MDA-MB-231 ( $<<0.01)$ lines (Fig. 1A). However, the gelatinolytic activities of MMP-2 and MMP-9 are significantly higher in cells cul- tured on Matrigel than those seeded on uncoated plastic (Fig. 2). MDA-MB-231 and Hs578T cell lines displayed higher MMP activity than less invasive and metastatic breast cancer cell lines. The expression of all analyzed MMP inhibitors was modulated by cell-Matrigel contact in highly invasive and metastatic cell lines (MDA-MB-231 and Hs578T) (Fig. 1B). In almost all cases, the expression of these MMP inhibitors was not regulated by Matrigel. The results presented in Fig. 1 were obtained with cells cultured for five days on plastic or Matrigel. The same results were observed when cells were cultured for three days (data not shown). The relative mRNA expression data was normalized using two different housekeeping genes, namely: $\beta$-tubulin and GAPDH, and similar expression profiles were obtained.

\section{Correlation between $m R N A$ expression of MMPs and their inhibitors in human breast cancer cell lines}

We evaluated whether a correlation between mRNA expression levels of MMPs and their inhibitors exists in the cell model of tumor progression used in this study. The gene expression values displayed by these five human breast cancer cell lines cultured either on plastic or Matrigel for 3 or 5 days, obtained by qRT-PCR, were subjected to statistical analysis using Pearson correlation test.

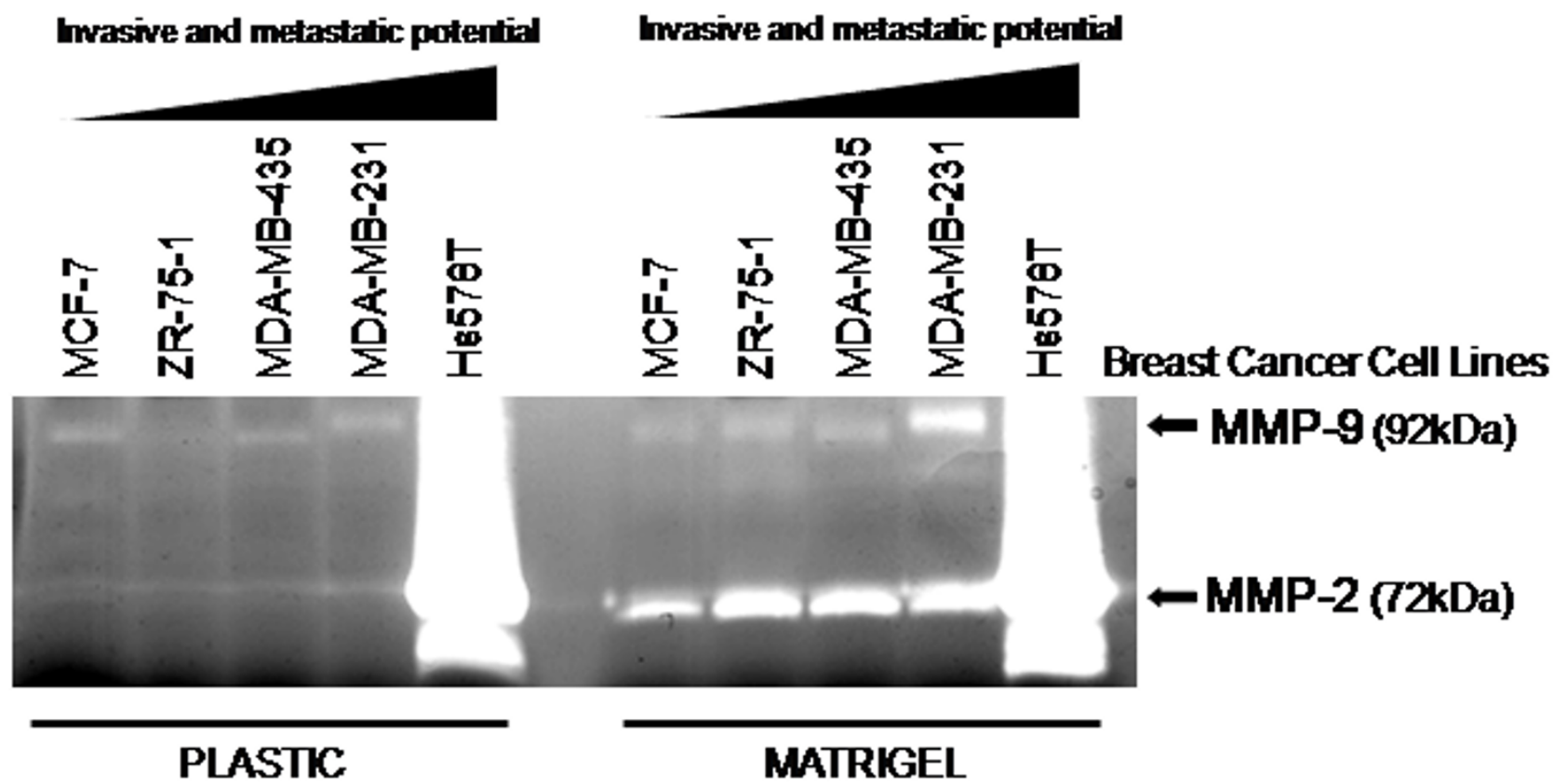

Figure 2

Representative zymogram of gelatin zymography analysis to detect the activity of secreted MMP-2 and MMP9 (three independent experiments) using conditioned medium from a panel of human breast cancer cell lines, displaying increased degrees of invasiveness and metastatic potential, cultured on different substrates (plastic or Matrigel). 
The results demonstrate a positive and significant correlation between the relative expression levels of all analyzed MMPs and MMP inhibitors. The expression of MMP-2 was an exception, since it significantly correlated only with MMP-14, TIMP-1 and RECK expression (Table 3).

\section{mRNA expression levels of MMPs and their inhibitors in samples of primary breast tumors and adjacent non-tumor tissues}

In order to validate the data obtained from breast cancer cell lines (Fig. 1), 72 samples of invasive ductal breast carcinomas and 30 samples of adjacent non-tumor tissues were selected and analyzed by qRT-PCR. The results (Fig. 3) demonstrate that the relative expression levels of MMP2 and MMP-14 of tumor samples were significantly higher than those of adjacent non-tumor tissue $(\mathrm{p}=0.0202$ and $\mathrm{p}<0.0001$, respectively). Furthermore, the samples derived from tumors showed a higher MMP-9 expression tendency than the adjacent non-tumor tissue specimens. TIMP-1 and TIMP-2 gene expression levels were significantly lower in tumors than in adjacent non-tumor tissue samples ( $\mathrm{p}=0.0169$ and $\mathrm{p}=0.0127$, respectively). A similar trend was verified for RECK expression levels. These results were normalized using two different housekeeping genes ( $\beta$-actin and HPRT), yielding similar expression profiles.

Table 3: Correlation between MMPs and their inhibitors in human breast cancer cell lines

\begin{tabular}{lllll}
\hline \multicolumn{1}{c}{ Pearson Correlation Test } & $\mathrm{R}$ & $\mathrm{p}$-value & $\mathrm{n}$ \\
\hline MMP-2 & MMP-9 & -0.17 & $\mathrm{p}=0.1625$ & 69 \\
& MMP-14 & 0.47 & $\mathrm{p}<0.0001$ & 72 \\
& TIMP-1 & 0.25 & $\mathrm{p}=0.0346$ & 72 \\
& TIMP-2 & 0.10 & $\mathrm{p}=0.3979$ & 69 \\
& RECK & 0.44 & $\mathrm{p}<0.0001$ & 72 \\
\hline MMP-9 & MMP-14 & 0.75 & $p<0.0001$ & 70 \\
& TIMP-1 & 0.36 & $p=0.0022$ & 71 \\
& TIMP-2 & 0.52 & $p<0.0001$ & 67 \\
& RECK & 0.32 & $p=0.0059$ & 71 \\
\hline \multirow{2}{*}{ MMP-14 } & TIMP-1 & 0.52 & $p<0.0001$ & 75 \\
& TIMP-2 & 0.67 & $p<0.0001$ & 70 \\
& RECK & 0.67 & $p<0.0001$ & 74 \\
\hline TIMP-1 & TIMP-2 & 0.68 & $p<0.0001$ & 71 \\
& RECK & 0.66 & $p<0.0001$ & 75 \\
\hline TIMP-2 & RECK & 0.80 & $p<0.0001$ & 70
\end{tabular}

Correlations between gene expressions data were calculated using Pearson Correlation test.

(n) Number of analyzed samples

(r) Pearson correlation coefficient
Balance between relative gene expression levels of MMPs and their inhibitors in samples of primary breast tumors and adjacent non-tumor tissues

The differences in the enzyme/inhibitor balance between tumor tissue specimens and adjacent non-tumor tissue samples were evaluated by calculating the MMPs/MMP inhibitors ratio values by using the mRNA expression levels data obtained by qRT-PCR. The results indicated that the ratios between MMP-2/RECK, MMP-9/RECK and MMP-14/RECK were significantly higher in the tumor than in adjacent non-tumor tissue samples $(\mathrm{p}=0.0024, \mathrm{p}$ $=0.0001$ and $\mathrm{p}<0.0001$, respectively) (Figure 4). The same results were obtained for the ratios between MMP-9/ TIMP-1, MMP-2/TIMP-2, MMP-14/TIMP-1 and MMP-14/ TIMP-2 $(\mathrm{p}=0.0271, \mathrm{p}=0.0012, \mathrm{p}<0.0001$ and $\mathrm{p}<$ 0.0001 , respectively). The same was obtained for the ratio between the sum of relative expression values of all MMPs (MMP-2, MMP-9 and MMP-14) and MMPs inhibitors (TIMP-1, TIMP-2 and RECK) $(\mathrm{p}<0.0001)$

\section{Correlation between MMPs, TIMPs and RECK expression and clinical-pathological variables in human breast carcinomas}

The association of relative mRNA expression levels of MMPs, TIMPs and RECK with clinical-pathological data was statistically verified by Chi-Square test. MMP expression showed no significant association with the clinical data evaluated in this study (see Additional Data). The PR status presented a significant association with TIMP-1 gene expression ( $\mathrm{p}=0.020)$ (data not shown). Statistically significant associations were not observed between the relative expression of either TIMP-2 or RECK and the clinical variables analyzed.

The values of relative gene expression of MMPs and their inhibitors from breast tumor tissue samples were subjected to Pearson's test for correlation. The expression levels of TIMP-2 and RECK in tumoral samples showed a significant positive correlation with the gene expression of MMP-2 and MMP-14 (Table 4) ( $\mathrm{p}<0.0001$ for all these correlations).

\section{Discussion}

Development of metastasis is the most critical parameter for determination of survival in breast cancer patients. Patients diagnosed and treated before further extension of the tumor present higher cure rate [2-4]. The role of MMPs and their specific inhibitors in the metastatic process is well established. Nowadays, there are more than 20 MMPs identified in humans, and several MMP inhibitors, each one of these molecules being involved in different steps of tumor progression $[20,21]$. In spite of the complexity of MMPs/MMP inhibitors system, all previous studies which analyzed the status of these molecules during mammary tumor progression only focused on a small 

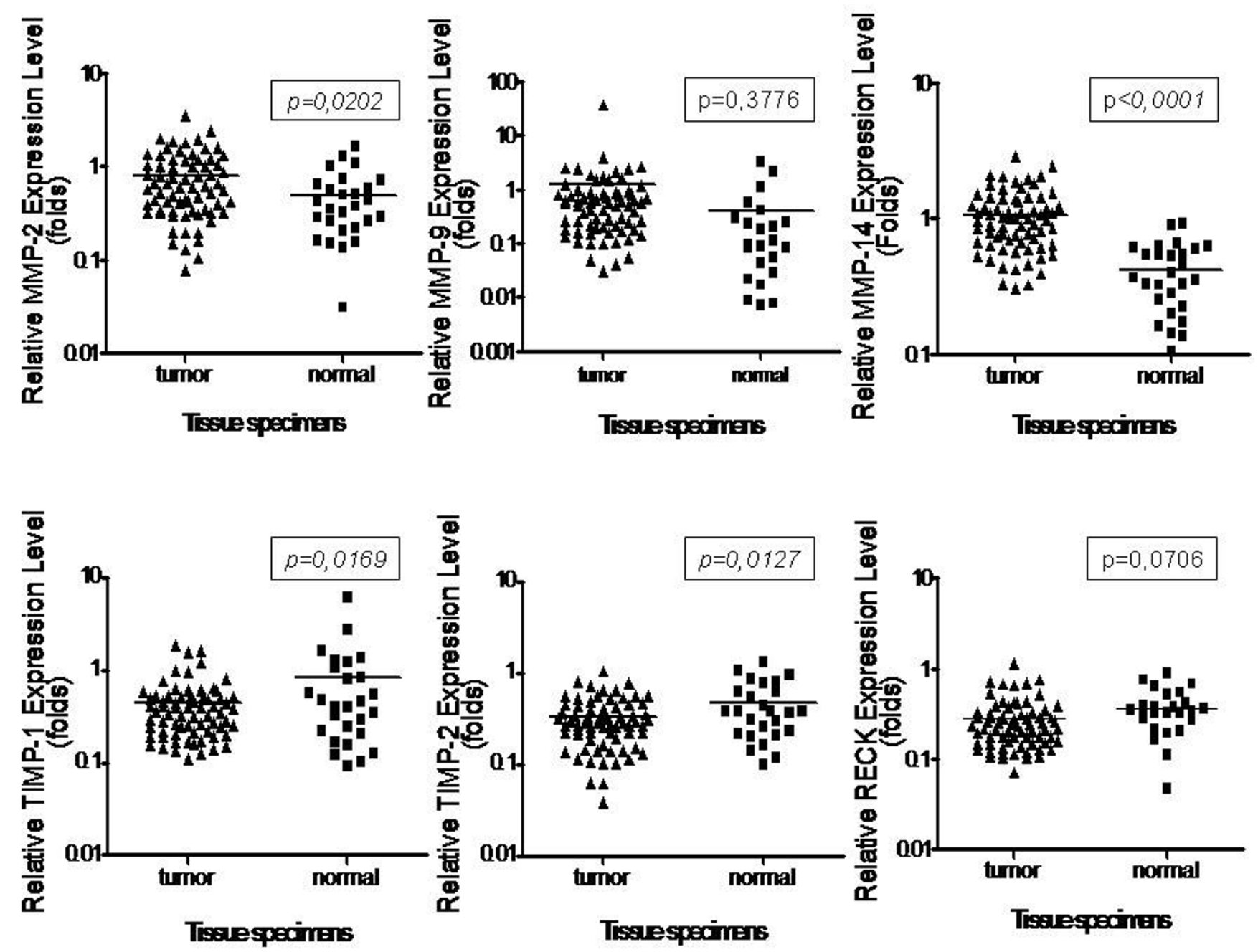

Figure 3

Expression levels of MMPs and their inhibitors by qRT-PCR. It was performed using total RNA from samples of primary breast tumors and adjacent normal border. $\beta$-actin was used to normalize the values. The statistical significance was determined using Student's $t$ test.

number of MMPs/MMP inhibitors in a limited number of models. Here, we proposed a more extensive approach by analyzing the mRNA expression levels of different MMPs (MMP-2, MMP-9 and MMP-14) and MMP inhibitors by qRT-PCR (TIMP-1, TIMP-2 and RECK) in several models (five human breast cancer cell lines, 72 primary breast tumors and 30 adjacent normal tissues).

The verified mRNA expression levels, obtained by qRTPCR, suggested that breast cancer progression from premalignant stages to highly invasive and metastatic carcinomas could be accompanied by increased expression of MMPs and their inhibitors. The total RNA from a panel of five human breast cancer cell lines, displaying increased degrees of invasiveness and metastatic potential, were used to perform this quantitative RT-PCR assay. In the cell model used, the levels of all analyzed MMPs (MMP-2, MMP-9 and MMP-14) were, in almost all cases, higher in cell lines with elevated invasive and metastatic capacities (MDA-MB-435, MDA-MB-231 and Hs578T) when compared to less aggressive ones (MCF-7 and ZR-75-1). These results corroborate the data previously obtained by other groups, in which MMPs expression in breast cancer cell models positively correlates with a highly aggressive phenotype $[26,27]$. We found similar mRNA expression profiles for all analyzed MMP inhibitors (TIMP-1, TIMP-2 and RECK). At first sight, these results seem contradictory, since these molecules were described as MMP inhibitors. However, elevated mRNA expression levels of TIMP-1 and TIMP-2 have been previously detected in breast cancer cell lines with high invasive and metastatic potential [28]. Furthermore, several reports describe TIMPs as multifunc- 

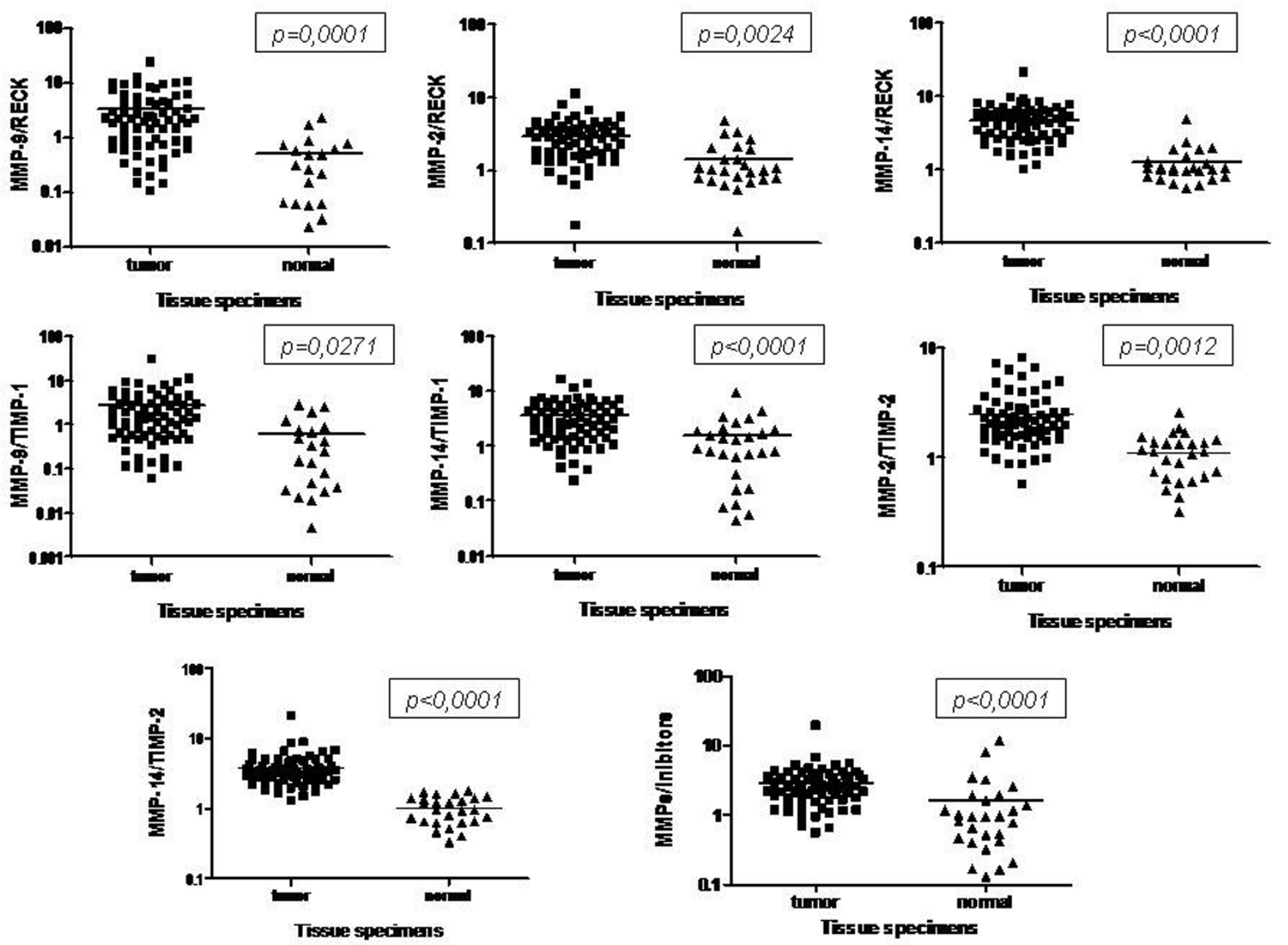

Figure 4

Analysis of the proteinase/inhibitor balance at transcriptional levels by qRT-PCR using total RNA from samples of primary breast tumors and adjacent normal border. $\beta$-actin was used to normalize the values. The statistical significance was determined using Student's $t$ test.

tional molecules [8]. Thus, these molecules were both able to suppress and to promote tumor progression [8].

On the other hand, high expression levels of RECK, a membrane-associated MMP regulator protein, which is able to suppress tumor invasion and metastasis, were associated with better prognosis in several types of tumor, including breast carcinomas $[18,19]$. However, our results demonstrate that RECK mRNA expression level is increased during breast cancer progression. Thus, at first sight, these data seem to be at variance with the previous studies, suggesting that increased RECK levels could be associated not with better prognosis, but with late clinical stages. Nevertheless, other reports demonstrated that elevated levels of RECK were associated with better prognosis only for patients in late clinical stages $[29,30]$. Therefore, tumors that present overexpression of RECK could display a better clinical course, depending on the enzyme/inhibitor context. Thus, induction of RECK gene expression, observed during breast cancer progression, could be a cellular response to enhanced expression and activity of MMPs. In this context, the ECM proteolysis equilibrium could be maintained by re-establishment of the MMPs/ inhibitors balance.

The role of cell-ECM elements interaction in regulation of expression and activity of these molecules was evaluated. The gelatin degradation ability of MMP-2 and MMP-9, evaluated by zymography assays, was significantly increased in cultures seeded onto Matrigel, when compared to those seeded onto uncoated plastic. Moreover, in highly aggressive cell lines, enhanced MMP activity was 
Table 4: Correlation between expression of MMPs and their inhibitors in samples of primary breast tumors

\begin{tabular}{|c|c|c|c|c|}
\hline \multicolumn{2}{|c|}{ Pearson Correlation Test } & \multirow{2}{*}{$\begin{array}{l}r \\
0.06\end{array}$} & \multirow{2}{*}{$\begin{array}{l}P \text {-value } \\
P=0.6523\end{array}$} & \multirow{2}{*}{$\begin{array}{l}N \\
67\end{array}$} \\
\hline MMP-2 & MMP-9 & & & \\
\hline & MMP-I4 & 0.68 & $p<0.0001$ & 70 \\
\hline & TIMP-I & -1.3 & $p=0.2968$ & 70 \\
\hline & TIMP-2 & 0.65 & $p<0.0001$ & 70 \\
\hline & RECK & 0.64 & $p<0.0001$ & 70 \\
\hline \multirow[t]{4}{*}{ MMP-9 } & MMP-I4 & 0.17 & $p=0.1586$ & 67 \\
\hline & TIMP-I & 0.07 & $p=0.6005$ & 67 \\
\hline & TIMP-2 & 0.21 & $p=0.0925$ & 67 \\
\hline & RECK & 0.04 & $P=0.7245$ & 67 \\
\hline \multirow[t]{3}{*}{ MMP-I 4} & TIMP-I & -1.7 & $P=0.1474$ & 70 \\
\hline & TIMP-2 & 0.61 & $p<0.0001$ & 70 \\
\hline & RECK & 0.49 & $p<0.0001$ & 70 \\
\hline \multirow[t]{2}{*}{ TIMP-I } & TIMP-2 & 0.06 & $p=0.6375$ & 70 \\
\hline & RECK & -1.3 & $P=0.2702$ & 70 \\
\hline TIMP-2 & RECK & 0.42 & $p=0.0003$ & 70 \\
\hline
\end{tabular}

Correlations between gene expressions data were calculated using Pearson Correlation test.

(n) Number of analyzed samples

(r) Pearson correlation coefficient

observed in less invasive and metastatic breast cancer cells, corroborating the data obtained in mRNA expression analysis. However, among the analyzed proteases, only MMP-2 expression was significantly modulated by cell-ECM elements interaction. These results suggest that increased proteolytic activity is independent of transcriptional activation, corroborating previously published data [31]. Our results demonstrate that the transcript levels of all studied MMP inhibitors are significantly modulated by the reconstituted basal lamina. This regulation of TIMP-1, TIMP-2 and RECK mRNA levels by cell-Matrigel contact was significant only in highly invasive and metastatic cell lines. Therefore, the intense ECM degradation is correlated with increased MMP inhibitor expression. The ECM supplies mechanical support to cells and structural integrity to tissues [6,32]. Furthermore, ECM performs an instructive role, since it is a reservoir of cytokines, and of growth and differentiation factors, which can be discharged and/or activated during proteolysis of ECM elements [33] by MMPs, contributing to the crosstalk between tumor cells and the microenvironment [34]. Therefore, the high mRNA expression levels of MMP inhibitors, found in highly aggressive cell lines, probably reflects a cellular reaction mechanism to intense ECM remodeling, as previously discussed. Thus, during ECM degradation, an important factor involved in induction of TIMPs and RECK can be discharged and/or activated. Our results corroborate this hypothesis, since we demonstrated that ECM is important only in modulation of gene expression of MMP inhibitors and, moreover, only in highly invasive and metastatic cell lines. Therefore, we suggest that this negative feedback mechanism of induction of protease inhibitors, during breast cancer progression, occurs for the re-establishment of the $\mathrm{MMP} /$ inhibitors balance and, consequently, for homeostasis of ECM proteolysis.

Cellular models are commonly used in Cell and Molecular Biology studies due to the limited source of tissue samples. However, enrichment for malignant cells and absence of stroma may compromise comparisons between cell lines and tumors [35]. Therefore, to discard possible cell culture artifacts, we also analyzed the expression of MMPs and their inhibitors in primary breast cancer tumor samples by qRT-PCR. The results obtained demonstrate, in a more general scenario, that the mRNA expression levels of MMPs are significantly higher in tumor samples than in adjacent non-tumor tissues. On the other hand, TIMP-1, TIMP-2 and RECK gene expression levels were significantly lower in tumors when compared with adjacent normal tissues. Furthermore, our results demonstrate a significant positive correlation between the gene expression levels of these proteases and their inhibitors in primary breast tumors from patients. Therefore, we suggest that increased expression of genes responsible for ECM degradation is coordinately accompanied by increased expression of their specific inhibitors and that the levels of MMPs, TIMPs and RECK transcripts may be regulated by common factors and signaling pathways.

Corroborating other studies in breast cancer [10,36], we found no significant association between the mRNA expression levels of the MMPs analyzed and clinical-pathological data $[10,36]$. These results suggest that the MMPs may supply independent prognostic information. However, there are conflicting results on the prognostic value of these proteases in this model. These differences can, at least in part, be due to the different methodologies used and to possible modulation of MMPs by adjuvant systemic treatment $[37,38]$. Furthermore, the TIMP-1, TIMP2 and RECK transcript levels did not correlate with the clinical parameters from patients. The status of PR was an exception, which showed a significant correlation with TIMP-1 gene expression only. Likewise, we suggest that expression of the analyzed MMPs inhibitors may supply independent prognostic information.

\section{Conclusion}

Taken together, the results obtained demonstrate that MMPs and their specific inhibitors are overexpressed in more aggressive breast cancer cell lines. However, it is likely that each one of these molecules plays distinct roles in acquisition of the invasive and metastatic capacity. This 
complexity of the MMPs-inhibitors system is intensified by a strong correlation found between the expression levels of these key regulators of the metastatic process. Thus, we suggest that the expression analysis of only one of these molecules or the independent quantification of these molecular markers does not provide sufficient information to elucidate the pathological proteolytic mechanisms associated with the tumor. Therefore, simultaneous analysis of the expression status of these molecules could be a better parameter to determine the most adequate therapy for each patient.

\section{Abbreviations}

CM: conditioned medium; ECM: extracellular matrix; ER: estrogen receptor; MMP: matrix metalloproteinases; PR: progesterone receptor; qRT-PCR: quantitative reverse transcription polymerase chain reaction; RECK: reversioninducing cysteine-rich protein with Kazal motifs; SD: standard deviation; TIMP: tissue inhibitors of matrix metalloproteinases

\section{Competing interests}

The authors declare that they have no competing interests.

\section{Authors' contributions}

RCSF was responsible for most of the experimental work and interpretation of some of the results. LRG was responsible for data discussion and interpretation, statistical analysis and manuscript preparation. JSN, FCS and IDCGS were responsible for collecting the tumor samples used in this study. MCS participated in the study design, data discussion and supervision of the study. All authors read and approved the final manuscript.

\section{Additional material}

\section{Additional file 1}

Clinic-pathological data. The data provided represent the clinical pathological data from patients whose breast tumor or normal tissue samples were used in this study.

Click here for file

[http://www.biomedcentral.com/content/supplementary/14712407-9-20-S1.doc]

\section{Acknowledgements}

The excellent technical support of Zizi de Mendonça, Sandra Regina de Souza, Debora Cristina da Costa, Ricardo Krett de Oliveira, Patrícia Barros dos Santos and Guilherme Frutero is deeply appreciated. Thanks also to the critical reviewing of Letícia Labriola, María Giselle Peters and Wagner Montor. This work was supported by Fundação de Amparo a Pesquisa do Estado de São Paulo (FAPESP), Conselho Nacional de Pesquisa (CNPq), Financiadora de Estudos e Projetos (FINEP) and Pró-Reitoria da Universidade de São Paulo (PRP-USP).

\section{References}

I. Jemal A, Siegel R, Ward E, Hao Y, Xu J, Murray T, Thun MJ: Cancer statistics, 2008. CA Cancer J Clin 2008, 58(2):7I-96.

2. Lee JH, Welch DR: Suppression of metastasis in human breast carcinoma MDA-MB-435 cells after transfection with the metastasis suppressor gene, KiSS-I. Cancer Res 1997, 57( I 2):2384-2387.

3. Welch DR, Steeg PS, Rinker-Schaeffer CW: Molecular biology of breast cancer metastasis. Genetic regulation of human breast carcinoma metastasis. Breast Cancer Res 2000, 2(6):408-4I6.

4. Yang J, Mani SA, Donaher JL, Ramaswamy S, Itzykson RA, Come C, Savagner P, Gitelman I, Richardson A, Weinberg RA: Twist, a master regulator of morphogenesis, plays an essential role in tumor metastasis. Cell 2004, I I7(7):927-939.

5. Vernon AE, LaBonne C: Tumor metastasis: a new twist on epithelial-mesenchymal transitions. Curr Biol 2004, I4(I 7):R7|9-72I.

6. Itoh $\mathrm{Y}$, Nagase $\mathrm{H}$ : Matrix metalloproteinases in cancer. Essays Biochem 2002, 38:21-36.

7. Visse R, Nagase $H$ : Matrix metalloproteinases and tissue inhibitors of metalloproteinases: structure, function, and biochemistry. Circ Res 2003, 92(8):827-839.

8. Lambert E, Dasse E, Haye B, Petitfrere E: TIMPs as multifacial proteins. Crit Rev Oncol Hematol 2004, 49(3): I87-I 98.

9. Talvensaari-Mattila A, Paakko P, Turpeenniemi-Hujanen T: Matrix metalloproteinase-2 (MMP-2) is associated with survival in breast carcinoma. Br J Cancer 2003, 89(7): I 270- I 275.

10. Jones JL, Glynn P, Walker RA: Expression of MMP-2 and MMP-9, their inhibitors, and the activator MTI-MMP in primary breast carcinomas. J Pathol 1999, I89(2): I6I-I68.

II. Iwata H, Kobayashi S, Iwase H, Masaoka A, Fujimoto N, Okada Y: Production of matrix metalloproteinases and tissue inhibitors of metalloproteinases in human breast carcinomas. Jpn J Cancer Res 1996, 87(6):602-6II.

12. Schrohl AS, Christensen IJ, Pedersen AN, Jensen V, Mouridsen $H$, Murphy G, Foekens JA, Brunner N, Holten-Andersen MN: Tumor tissue concentrations of the proteinase inhibitors tissue inhibitor of metalloproteinases-I (TIMP-I) and plasminogen activator inhibitor type I (PAI-I) are complementary in determining prognosis in primary breast cancer. Mol Cell Proteomics 2003, 2(3): I64-I72.

13. Schrohl AS, Holten-Andersen MN, Peters HA, Look MP, Meijer-van Gelder ME, Klijn JG, Brunner N, Foekens JA: Tumor tissue levels of tissue inhibitor of metalloproteinase-I as a prognostic marker in primary breast cancer. Clin Cancer Res 2004, I O(7):2289-2298.

14. Remacle A, McCarthy K, Noel A, Maguire T, McDermott E, O'Higgins N, Foidart JM, Duffy MJ: High levels of TIMP-2 correlate with adverse prognosis in breast cancer. Int J Cancer 2000, 89(2): $|18-12|$.

15. Takahashi C, Sheng Z, Horan TP, Kitayama H, Maki M, Hitomi K, Kitaura Y, Takai S, Sasahara RM, Horimoto A, et al.: Regulation of matrix metalloproteinase-9 and inhibition of tumor invasion by the membrane-anchored glycoprotein RECK. Proc Natl Acad Sci USA 1998, 95(22): I3221-13226.

16. Oh J, Takahashi R, Kondo S, Mizoguchi A, Adachi E, Sasahara RM, Nishimura S, Imamura Y, Kitayama H, Alexander DB, et al.: The membrane-anchored MMP inhibitor RECK is a key regulator of extracellular matrix integrity and angiogenesis. Cell 200I, I 07(6):789-800.

17. Rhee JS, Coussens LM: RECKing MMP function: implications for cancer development. Trends Cell Biol 2002, I 2(5):209-2I I.

18. Clark JC, Thomas DM, Choong PF, Dass CR: RECK - a newly discovered inhibitor of metastasis with prognostic significance in multiple forms of cancer. Cancer Metastasis Rev 2007, 26(34):675-683.

19. Span PN, Sweep CG, Manders P, Beex LV, Leppert D, Lindberg RL: Matrix metalloproteinase inhibitor reversion-inducing cysteine-rich protein with Kazal motifs: a prognostic marker for good clinical outcome in human breast carcinoma. Cancer 2003, 97(II):27I0-27I5.

20. Chang C, Werb Z: The many faces of metalloproteases: cell growth, invasion, angiogenesis and metastasis. Trends Cell Biol 200 I, I I ( I I):S37-43. 
21. Sternlicht MD, Werb Z: How matrix metalloproteinases regulate cell behavior. Annu Rev Cell Dev Biol 200I, 17:463-5I6.

22. Bachmeier BE, Albini A, Vene R, Benelli R, Noonan D, Weigert C, Weiler C, Lichtinghagen R, Jochum M, Nerlich AG: Cell densitydependent regulation of matrix metalloproteinase and TIMP expression in differently tumorigenic breast cancer cell lines. Exp Cell Res 2005, 305(I):83-98.

23. Bachmeier BE, Nerlich AG, Lichtinghagen R, Sommerhoff CP: Matrix metalloproteinases (MMPs) in breast cancer cell lines of different tumorigenicity. Anticancer Res 200I, 2I(6A):382I-3828.

24. Haupt LM, Thompson EW, Trezise AE, Irving RE, Irving MG, Griffiths LR: In vitro and in vivo MMP gene expression localisation by In Situ-RT-PCR in cell culture and paraffin embedded human breast cancer cell line xenografts. BMC Cancer 2006, 6(I): 18

25. Pfaffl MW: A new mathematical model for relative quantification in real-time RT-PCR. Nucleic Acids Res 200I, 29(9):e45.

26. Balduyck M, Zerimech F, Gouyer V, Lemaire R, Hemon B, Grard G, Thiebaut C, Lemaire V, Dacquembronne E, Duhem T, et al.: Specific expression of matrix metalloproteinases $I, 3,9$ and $I 3$ associated with invasiveness of breast cancer cells in vitro. Clin Exp Metastasis 2000, 18(2): $171-178$.

27. Kousidou OC, Roussidis AE, Theocharis AD, Karamanos NK: Expression of MMPs and TIMPs genes in human breast cancer epithelial cells depends on cell culture conditions and is associated with their invasive potential. Anticancer Res 2004, 24(6):4025-4030

28. Yoshiji H, Gomez DE, Thorgeirsson UP: Enhanced RNA expression of tissue inhibitor of metalloproteinases-I (TIMP-I) in human breast cancer. Int J Cancer 1996, 69(2): I3I-134.

29. Takenaka K, Ishikawa S, Kawano Y, Yanagihara K, Miyahara R, Otake Y, Morioka Y, Takahashi C, Noda M, Wada H, et al.: Expression of a novel matrix metalloproteinase regulator, RECK, and its clinical significance in resected non-small cell lung cancer. Eur J Cancer 2004, 40(10):1617-1623.

30. Takenaka K, Ishikawa S, Yanagihara K, Miyahara R, Hasegawa S, Otake Y, Morioka Y, Takahashi C, Noda M, Ito H, et al.: Prognostic significance of reversion-inducing cysteine-rich protein with Kazal motifs expression in resected pathologic stage IIIA N2 nonsmall-cell lung cancer. Ann Surg Oncol 2005, I 2(10):817-824.

31. Azzam HS, Arand G, Lippman ME, Thompson EW: Association of MMP-2 activation potential with metastatic progression in human breast cancer cell lines independent of MMP-2 production. J Natl Cancer Inst I993, 85(2 I): I758-I764.

32. Ramirez $F$, Rifkin $D B$ : Cell signaling events: a view from the matrix. Matrix Biol 2003, 22(2): I0I-107.

33. Aumailley M, Gayraud B: Structure and biological activity of the extracellular matrix. J Mol Med 1998, 76(3-4):253-265.

34. Mueller MM, Fusenig NE: Friends or foes - bipolar effects of the tumour stroma in cancer. Nat Rev Cancer 2004, 4(I I):839-849.

35. Birgersdotter A, Sandberg R, Ernberg I: Gene expression perturbation in vitro - a growing case for three-dimensional (3D) culture systems. Semin Cancer Biol 2005, I 5(5):405-4I2.

36. Remacle AG, Noel A, Duggan C, McDermott E, O'Higgins N, Foidart JM, Duffy MJ: Assay of matrix metalloproteinases types I, 2, 3 and 9 in breast cancer. Br J Cancer 1998, 77(6):926-931.

37. Lebeau A, Muller-Aufdemkamp C, Allmacher C, Sauer U, Nerlich A, Lichtinghagen R, Lohrs U: Cellular protein and mRNA expression patterns of matrix metalloproteinases $-2,-3$ and -9 in human breast cancer: correlation with tumour growth. J Mol Histol 2004, 35(5):443-455.

38. Li HC, Cao DC, Liu Y, Hou YF, Wu J, Lu JS, Di GH, Liu G, Li FM, Ou ZL, et al.: Prognostic value of matrix metalloproteinases (MMP-2 and MMP-9) in patients with lymph node-negative breast carcinoma. Breast Cancer Res Treat 2004, 88(I):75-85.

\section{Pre-publication history}

The pre-publication history for this paper can be accessed here:

http://www.biomedcentral.com/1471-2407/9/20/prepub
Publish with Bio Med Central and every scientist can read your work free of charge

"BioMed Central will be the most significant development for disseminating the results of biomedical research in our lifetime. "

Sir Paul Nurse, Cancer Research UK

Your research papers will be:

- available free of charge to the entire biomedical community

- peer reviewed and published immediately upon acceptance

- cited in PubMed and archived on PubMed Central

- yours - you keep the copyright
BioMedcentral 